\title{
Asymptomatic (Subclinical) Meningitis in One of Premature Triplets with Simultaneous Enteroviral Meningitis: A Case Report
}

\author{
Ashish Gupta, M.D. ${ }^{1}$ Robert W. Tolan, M.D. ${ }^{2,3}$ \\ ${ }^{1}$ The Children's Hospital at Saint Peter's University Hospital \\ ${ }^{2}$ Department of Pediatrics, Division of Allergy, Immunology, and \\ Infectious Diseases, The Children's Hospital at Saint Peter's \\ University Hospital, New Brunswick, New Jersey \\ ${ }^{3}$ Drexel University College of Medicine, Philadelphia, Pennsylvania
}

\author{
Address for correspondence and reprint requests Robert W. Tolan, \\ Jr, M.D., MOB 3110, 254 Easton Avenue, New Brunswick, NJ 08901 \\ (e-mail: rtolan@saintpetersuh.com).
}

Am J Perinatol Rep 2012;2:15-18.

\author{
Abstract \\ Keywords \\ - enterovirus infection \\ - asymptomatic aseptic \\ meningitis \\ - prematurity \\ - simultaneous \\ infection \\ - triplets
}

Most enterovirus infection in the neonate and young infant is asymptomatic, but serious disease may occur, especially if acquired perinatally. We report the first case, to our knowledge, of asymptomatic enterovirus aseptic meningitis, and of concurrent enterovirus aseptic meningitis in premature triplets. Ten-week-old, 31-week-estimated gestational age premature triplet boys were diagnosed with enterovirus aseptic meningitis on the same day. Two of the triplets developed symptoms on the day of admission, while the third remained symptom free throughout the infection. All three recovered completely and are healthy more than a decade later.
Enteroviruses are nonenveloped, single-stranded, positivesense viruses in the Picornaviridae family and include poliovirus, coxsackievirus groups $\mathrm{A}$ and $\mathrm{B}$, echoviruses, and the numbered enteroviruses. To date, more than 100 serotypes have been identified. ${ }^{1}$ Primarily enteroviruses are spread person-to-person by the fecal-oral route; respiratory and vertical transmission occur less frequently. The pathophysiology of enterovirus infection is illustrated in - Fig. 1. Intrauterine infection is rare, but often fatal. ${ }^{2,3}$ Postnatal enterovirus infection tends to be more common, and more serious, when acquired at younger ages. Sixty to seventy percent of neonates diagnosed with enterovirus infection in the first 10 days of life are infected at the time of delivery. ${ }^{4}$ Of those infected in the first month of life, up to $25 \%$ may have serious disease. ${ }^{4}$ However, most severe enteroviral infections occur in the first 2 weeks of life, manifestations of which may include overwhelming sepsis-like syndrome, ${ }^{5}$ meningoencephalitis, cardiovascular collapse, myocarditis, ${ }^{6}$ pneumonia, hepatitis, and/or coagulopathy. ${ }^{4,7,8}$ Risk factors for severe disease in neonates include absence of neutralizing antibody, maternal illness in the perinatal period, prematurity, onset in the first few days of life, and infection with more virulent viruses. ${ }^{7}$ Family members, hospital staff, and other caregivers also transmit infection to newborns, especially during the peak season. ${ }^{4}$ Outbreaks of necrotizing enterocolitis-like gastrointestinal infection in the newborn intensive care nursery have been reported. ${ }^{9}$

Infection is most prevalent in young children and symptomatic infection (disease) is more frequent in males, in the summer months (in temperate regions), and in crowded conditions. In older infants and children, common manifestations of enteroviral infection include nonspecific febrile illness, gastroenteritis, herpangina, pharyngitis, hand foot and mouth disease, other exanthemata, upper respiratory tract infection (URTI), and conjunctivitis. ${ }^{10}$ Among those beyond the neonatal period, infection in the first months of life tends to be more severe (and more frequently results in hospitalization). ${ }^{11-13}$ Sepsis-like syndrome (including received

September 1, 2011

accepted

September 16, 2011

published online

November 25, 2011
Copyright $\odot 2012$ by Thieme Medical Publishers, Inc., 333 Seventh Avenue, New York, NY 10001, USA. Tel: +1(212) 584-4662.
DOI http://dx.doi.org/ 10.1055/s-0031-1296029. ISSN 2157-6998. 


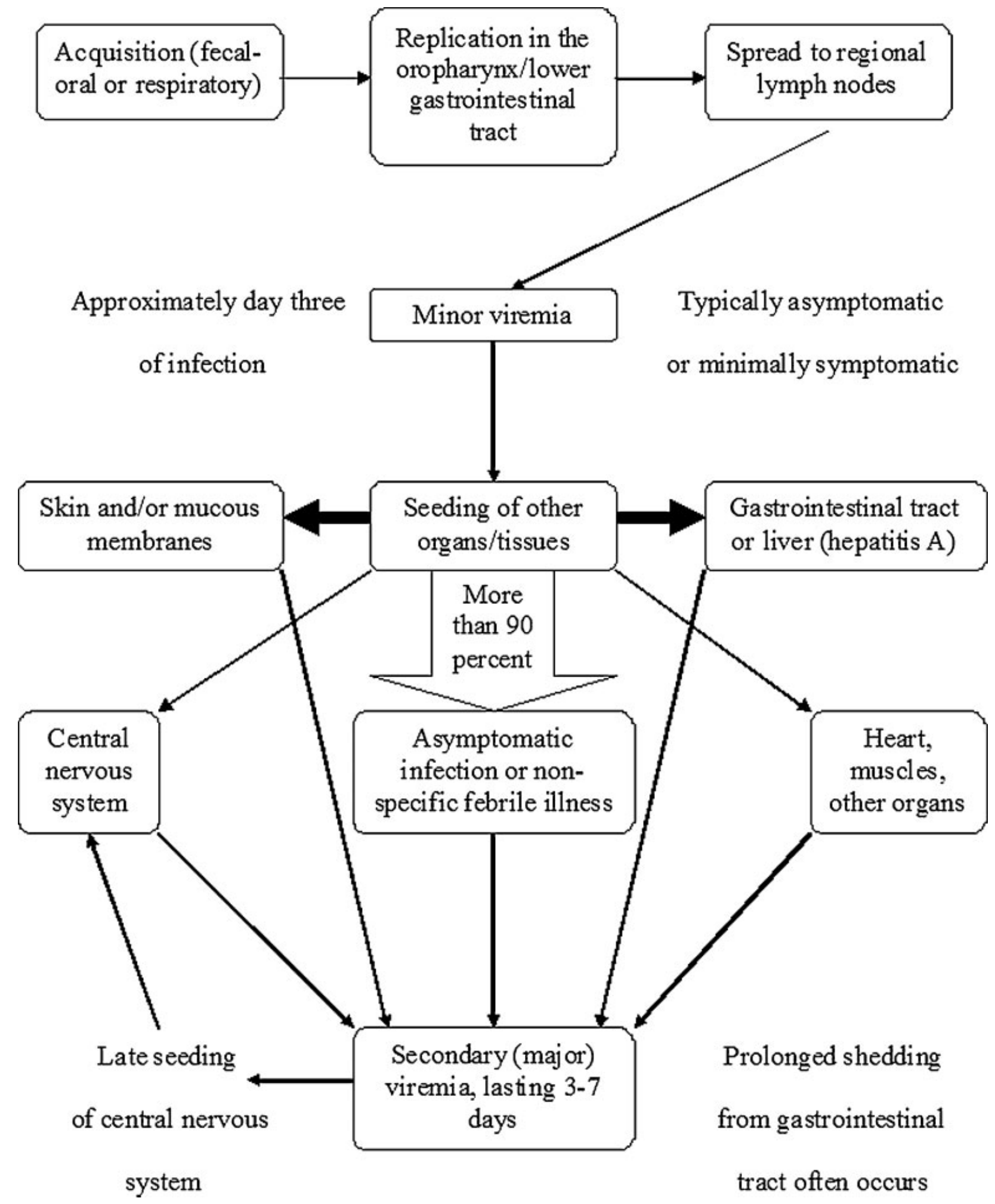

Figure 1 The pathophysiology of enterovirus infection.

multiorgan failure), hepatitis, myopericarditis, paralysis, and central nervous system (CNS) involvement are among the more serious manifestations of enterovirus-caused disease in older infants and children. ${ }^{10}$ Enteroviral infection has been implicated in cases of sudden infant death syndrome in at least one study, as well. ${ }^{14}$ However, even in the first month of life, $79 \%$ of infected neonates are asymptomatic. $^{15}$ 
Table 1 Clinical and Cerebrospinal Fluid Features of the Triplets

\begin{tabular}{|c|c|c|c|c|c|c|c|c|}
\hline & \multirow{2}{*}{$\begin{array}{l}\text { Maximum } \\
\text { Temperature }\end{array}$} & \multicolumn{7}{|c|}{ Cerebrospinal Fluid Findings } \\
\hline & & $\begin{array}{l}\text { Glucose } \\
\text { (mg/dL) }\end{array}$ & $\begin{array}{l}\text { Protein } \\
\text { (mg/dL) }\end{array}$ & $\begin{array}{l}\text { Red Blood } \\
\text { Cells } \\
(\text { Per } \mu \mathrm{L})\end{array}$ & $\begin{array}{l}\text { White Blood } \\
\text { Cells } \\
(\text { Per } \mu \mathrm{L})\end{array}$ & $\begin{array}{l}\text { Polymorpho- } \\
\text { nuclear } \\
\text { Leukocytes } \\
\text { (\%) }\end{array}$ & $\begin{array}{l}\text { Lymphocytes } \\
\text { (\%) }\end{array}$ & $\begin{array}{l}\text { Monocytes } \\
(\%)\end{array}$ \\
\hline Triplet A & 98.6 & 44 & 102 & 19 & 773 & 20 & 60 & 20 \\
\hline Triplet B & 100.6 & 37 & 96 & 321 & 11 & 25 & 57 & 17 \\
\hline Triplet C & 101.0 & 44 & 58 & 8 & 445 & 35 & 10 & 55 \\
\hline
\end{tabular}

\section{Case Report}

Ten-week-old male triplets were born at 31 weeks' gestation following a pregnancy complicated by preterm labor and growth failure of triplet B. Cesarean delivery occurred when their mother had impending hypertensive crisis. Following an unremarkable 1-month stay in the newborn intensive care unit, they were sent home in August with their parents, a 20-month-old brother who attended daycare, and the grandparents. Their mother and brother were sick with URTI and the grandmother had acute gastroenteritis and bronchitis. All three triplets developed URTI $\sim 2$ weeks before readmission to the hospital.

At 10 weeks of age, one of the triplets (triplet C) was found to be fussier than usual with increased spitting up. His temperature was $101 \mathrm{~F}$. He was admitted, evaluated, and treated for serious bacterial infection due to his prematurity and fever. His physical examination was normal except for fever and fussiness. His sibling (triplet B) also felt warm to touch and was found to have a temperature of 100.6 F. He was similarly evaluated later the same day and treated for serious bacterial infection. His physical examination was completely normal at the time of admission except for fever. Triplet A was admitted later the same day due to the cerebrospinal fluid (CSF) results of the other two triplets. At the time of admission and throughout his hospitalization, he was afebrile and had a normal examination. Important features of the clinical course of the triplets and the CSF findings are summarized in - Table 1.

All three triplets were initially treated with ampicillin and cefotaxime until bacterial cultures of blood, urine, and CSF were negative. Triplet $B$ required one bolus of crystalloid and a brief course of supplemental oxygen therapy for episodes of bradycardia, which resolved promptly. Enterovirus polymerase chain reaction (PCR) testing was positive on CSF from all three newborns. They recovered completely and remain healthy more than a decade later.

\section{Discussion}

Aseptic meningitis is the most common CNS infection and enteroviruses are the most commonly identified etiology. ${ }^{16,17}$ In a cohort of 227 children aged less than 24 months with enteroviral aseptic meningitis, $63.5 \%$ were less than 8 weeks old and $84.1 \%$ were less than 16 weeks old. ${ }^{16}$ The most common symptoms were fever in $88 \%$ and irritability in 79\%. Thirty percent had symptoms of URTI. Evidence of meningeal irritation was noted in only $8.7 \%$, however. ${ }^{16}$ Asymptomatic enteroviral meningitis has not been reported, to the best of our knowledge.

The CSF profiles of bacterial and viral meningitis may overlap, particularly during the earliest stages of viral meningitis, before a mononuclear predominance is established. In a series of 17 patients with enterovirus meningitis aged less than 2 months, $62.5 \%$ demonstrated a predominance of polymorphonuclear leukocytes in the CSF and 64\% had hypoglycorrhachia. ${ }^{18}$ In the aseptic meningitis cohort of 227 patients, median white blood count was $103 / \mathrm{mm}^{3}$ (with a range of 0 to $4050 / \mathrm{mm}^{3}$ ) with median neutrophil percentage of $26 \%$ (range 0 to $100 \%$ ). ${ }^{16}$ The median CSF protein concentration was $67 \mathrm{mg} / \mathrm{dL}$ (range 6 to $550 \mathrm{mg} / \mathrm{dL}$ ) and median glucose concentration was $52 \mathrm{mg} / \mathrm{dL}$ (range 24 to $122 \mathrm{mg}$ / $\mathrm{dL}) .{ }^{16}$ It is interesting that triplet $\mathrm{A}$, who was fever free and asymptomatic, had the highest CSF protein and the most white blood cells present in the CSF.

The etiologic diagnosis of viral meningitis requires positive identification of a virus from CSF or other site. ${ }^{17}$ Although virus culture was the gold standard diagnostic test, PCR for enterovirus detection performed on CSF is a sensitive, specific, rapid, and readily available method for the diagnosis of enteroviral meningitis. ${ }^{19}$ Treatment for aseptic meningitis caused by enterovirus infection is essentially supportive, although the Collaborative Antiviral Study Group is conducting a randomized, placebo-controlled therapeutic trial of the antiviral, pleconaril, for severe neonatal enteroviral infection. $^{4}$

Aseptic meningitis is an unusual complication of enteroviral infection, resulting from seeding of the CNS during primary or secondary (major) viremia (-Fig. 1). One case of intrauterine infection of twins whose mother developed chorioamnionitis at 34 weeks' gestation documented enterovirus in the CSF of both premature neonates. ${ }^{2}$ Although concurrent enteroviral aseptic meningitis in family members has been reported rarely, ${ }^{20}$ simultaneous disease acquired postnatally in twins or triplets has not (to the best of our knowledge). Antibody-mediated immunity is of primary 
importance in protection against enteroviral infection, and these premature siblings likely lacked transplacental antibody to their virus type. Both the uncommon occurrence of enteroviral aseptic meningitis (relative to all enterovirus infection in humans) and the rarity of concurrent aseptic meningitis in family members suggest that host genetic factors must play an as yet undefined role in the progression of enteroviral infection to involve the CNS.

\section{Acknowledgments}

We wish to thank the staff of the Saint Peter's University Hospital Medical Library for ongoing assistance and Dr. Shakuntala Chandra, Dr. Lawrence Frenkel, Dr. Carlos Lastra, and Dr. Sharada Polam for thoughtful review of the manuscript.

\section{References}

1 Khetsuriani N, Lamonte-Fowlkes A, Oberst S, Pallansch MA; Centers for Disease Control and Prevention. Enterovirus surveillance-United States, 1970-2005. MMWR Surveill Summ 2006; 55(8, SS08):1-20

2 Strong BS, Young SA. Intrauterine coxsackie virus, group B type 1, infection: viral cultivation from amniotic fluid in the third trimester. Am J Perinatol 1995;12(2):78-79

3 Willems A, Benne CA, Timmer A, Bergman KA. Fatal illness associated with pulmonary hypertension in a neonate caused by intrauterine echovirus 11 infection. Am J Perinatol 2006;23(1): 59-61

4 Collaborative Antiviral Study Group Study 106 Aims. Available at: http://clinicaltrials.gov/ct2/show/NCT00031512. Accessed August 9, 2011

5 Kazzi NJ, Cepeda EE, Budev H. Fatal echovirus type 7 in a premature infant. Am J Perinatol 1988;5(3):236-238
6 Freund MW, Kleinveld G, Krediet TG, van Loon AM, VerboonMaciolek MA. Prognosis for neonates with enterovirus myocarditis. Arch Dis Child Fetal Neonatal Ed 2010;95(3):F206-F212

7 Abzug MJ. Presentation, diagnosis, and management of enterovirus infections in neonates. Paediatr Drugs 2004;6(1):1-10

8 Tebruegge M, Curtis N. Enterovirus infections in neonates. Semin Fetal Neonatal Med 2009;14(4):222-227

9 Birenbaum E, Handsher R, Kuint J, et al. Echovirus type 22 outbreak associated with gastro-intestinal disease in a neonatal intensive care unit. Am J Perinatol 1997;14(8):469-473

10 Pasquinelli L. Enterovirus infections. Pediatr Rev 2006;27(2): e14-e15

11 Morens DM. Enteroviral disease in early infancy. J Pediatr 1978;92 (3):374-377

12 Dagan R. Nonpolio enteroviruses and the febrile young infant: epidemiologic, clinical and diagnostic aspects. Pediatr Infect Dis J 1996;15(1):67-71

13 Hawkes MT, Vaudry W. Nonpolio enterovirus infection in the neonate and young infant. Paediatr Child Health (Oxford) 2005;10(7):383-388

14 Grangeot-Keros L, Broyer M, Briand E, et al. Enterovirus in sudden unexpected deaths in infants. Pediatr Infect Dis J 1996;15(2):123128

15 Jenista JA, Powell KR, Menegus MA. Epidemiology of neonatal enterovirus infection. J Pediatr 1984;104(5):685-690

16 Rorabaugh ML, Berlin LE, Heldrich F, et al. Aseptic meningitis in infants younger than 2 years of age: acute illness and neurologic complications. Pediatrics 1993;92(2):206-211

17 Berlin LE, Rorabaugh ML, Heldrich F, Roberts K, Doran T, Modlin JF Aseptic meningitis in infants $<2$ years of age: diagnosis and etiology. J Infect Dis 1993;168(4):888-892

18 Chiou CC, Liu WT, Chen SJ, et al. Coxsackievirus B1 infection in infants less than 2 months of age. Am J Perinatol 1998;15(3): 155-159

19 Schlesinger Y, Sawyer MH, Storch GA. Enteroviral meningitis in infancy: potential role for polymerase chain reaction in patient management. Pediatrics 1994;94(2 Pt 1):157-162

20 Faulkner RS, MacLeod AJ, Van Rooyen CE. Virus meningitis-seven cases in one family. Can Med Assoc J 1957;77(5):439-444 